\section{NOTE ON A CASE OF ARTIFICIAL PNEUMOTHORAX.}

BY DR. W. HOLMBOE,

MEDICAI DIRECTOR OF MIESNALIEN SANATORIUM, NORWAY.

THE following interesting case is that of an English medical graduate who was admitted to the sanatorium in the autumn of 1906 under the care of my predecessor, Dr. Sömme, and who allows me to send this note to THE LANCET. On admission there were signs of recent but extensive disease in the left lung, the right lung being then practically normal. During the following two years the patient was treated as an invalid, was largely confined to his bed, had considerable cough and expectoration, and subfebrile temperature. Besides the usual sanatorium treatment, rectal injections of Marmorek's serum and subcutaneous injections of tuber culin (Denys) were tried. The serum was a failure, but some improvement followed the tuberculin injections until the higher doses were reached, when the expectoration became more profuse, and lassitude and weakness followed. The tuberculin treatment was therefore given up. Early in February, 1909, the temperature was still subfebrile and the condition of the lungs was as follows. Left lung: Over the whole lung the normal resonance was absent on percussion. Over the second and third intercostal spaces the percussion note was "boxy." Belind there was dulness increasing towards the base. There was deficient air entry over the whole, and after coughing râles were audible every where. Over the base behind rhonchi and sibili could also be heard. Right lung: There was slight dulness over the apex in front and behind. Over the apex expiration was loud and prolonged. No adventitious sounds could be heard except over a small area at the angle of the scapula, where a few ritles were audible.

As practically the whole of the left lung was involved and the prognosis was bad, treatment by compression or by artificial pneumothorax was decided on. Saugman's modification of Forlanini's nitrogen pump was employed. The hollow needle was inserted into the sixth space in the anterior axillary line. The manometric oscillations were well marked, showing a negative pressure of - 14 centimetres water on inspiration and - 6 centimetres on expiration. The eye of the needle was therefore clearly between the two surfaces of the pleura and nowhere else; 180 cubic centimetres of nitrogen were then admitted in three portions. The operation was followed by considerable dyspnea and a dragging pain which caused a restless night in spite of an injection of morphine. Next day 275 cubic centimetres were injected, after which the pain gradually disappeared, but dyspnoea on the slightest movement remained very severe. The injections were repeated at intervals of two to three days at first. Later, when the pneumothorax became complete, the injections were given at intervals of one to two weeks, and after the treatment had lasted a year an interval of one month was allowed.

On the evening of the day of the first injection the temperature (rectal) rose to $100^{\circ} \mathrm{F}$.; it then gradually fell to normal in the course of ten days. After confinement to his bed for three weeks the patient was able to get up and walk, although this caused considerable dyspricea at first. Later this symptom largely disappeared, and even after a recent injection with a positive intrapleural pressure of 10 centimetres of water on expiration the patient was able to walk briskly on a flat road. The cough and expectoration decreased gradually and had completely disappeared by midsummer. Over the left lung the characteristic signs of a pneumothorax were present. The cardiac dulness was completely lost, and the heart sounds were distant and muffed. The limits of the left pleura extended to about two inches to the right of the middle line in front. The pneumothorax therefore was very extensive and overlapped the left margin of the right lung. The condition of the right lung has improved. A Roentgen photograph shows that the heart is completely displaced over to the right side of the chest where it is embedded in the right lung. The left lung is shown compressed from below upwards and to the right. By its apex it is still adherent to the surrounding structures. It is extranrdinary that with the heart so much displaced and the only lang in use compressed by the heart below, by the pneumothorax in front and to the left, and by cicatricial tissue in the apex. the pulse should be as low as 70 and that dyspncea should follow only considerable exertion.

At the present time the patient is up all day, he has neither cough nor expectoration, his temperature and pulse are normal, and his weight is about 20 pounds greater than on admission. He works several hours a day, and in my absence has satisfactorily carried out my duties for several weeks. In spite of the fact that a private sanatorium admits a great number of cases in an advanced stage of the disease, the opportunities for applying this treatment are limited, as the disease is generally too extensive in the sounder of the two lungs. Twice pleural adhesions proved a bar to the treatment at the outset. In four cases the sounder of the two lungs was too much involved for any lasting good to result, and in four cases excellent results, similar to that described above, were obtained.

Lillehammer, Norway.

\section{A DERMOID CYST OF THE TESTICLE ASSOCIATED WITH A NEW GROWTH.}

By F. J. F. BARRINGTON, F.R.C.S. ENG., HOUSE SURGEON TO ST. PETER'S HOSPITAL.

Clinical history.-The patient was aged 42 years, married, but had no children. He was admitted into St. Peter's Hospital on account of a swollen right testicle. The right testicle had always been larger than the left; when a child the patient remembered it being "pierced" by a medical man. The testicle had been gradually increasing in size for from three to four months. Beyond an aching in the groin when a suspender was not worn there was no pain. He had had two attacks of gonorrhoea, but denied having had syphilis. Before admission he had been treated as an out. patient for from three to four weeks with potassium iodide; in this time the swelling became larger owing to the development of a hydrocele.

On admission the vas and cord were normal. There was a solid enlargement of the testicle with a hydrncele of the tunica vaginalis; the epididymis could not be differentiated; the swelling was nowhere adherent to the skin. There was no testicular sensation, but slight tenderness on hard pressure. There was no palpable enlargement of the lumbar glands. The left testicle appeared normal. The clinical diagnosis rested between tertiary syphilis and a neoplasm. The testicle was explored by opening the tunica vaginalis, which contained about 5 ounces of clear, straw-coloured fluid. The testicle was found to be swollen and to have smooth bosses on the surface, which did not appear to be cystic. Orchidectomy was then performed in the usual way.

The patient was seen between six and seven months after the operation; he was then quite well and had no signs 0 local recurrence or secondary deposits in the abdomen.

Macrosoopio examination. - The parts removed consist of the right testicle, tunica vaginalis, and about 3 centimetres of the spermatic cord (Fig. 1). The parietal layer of the tunica vaginalis has been incised vertically and everted. The tunica vaginalis is not thickened or congested; its surface is quite smooth, and there is no lymph deposited on it. The visceral layer covers a smooth, slightly bossy, oval swelling. measuring 8 by 5 centimetres, and occupying the usual position of the testicle. A vertical section through the swelling shows the following three structures contained within the tunica albuginea, from above downwards: a dermoid cyst, a lobulated new growth, and normal testiculat substance.

The interior of the cyst measures $2 \frac{1}{2}$ by 4 centimetres; it is filled with a mixture of hair and white sebaceous débris. The hair is fair brown in colour, about the same as that of the patient. The interior of the cyst is roughly oval in shape, but there are two ridges projecting into it, one runnins transversely round the inner or left half of the cyst below it middle, and the other projecting upwards from the lower part of the cost wall on its right side and running in $a$ coronal plane; in the former ridge are some thin plates giving a bony sensation to the point of a metal instrument There are no structures resembling teeth in the cyst.

The tanica altraginea passes off the cyst wall on to tie growth. This is yellow ochre coloured and divided int 